\title{
Miopatia pós anestésica em equino anêmico: relato de caso
}

Aline Mota Engbruch;, Sérgio Grandisoli Garcia Filho, Maria Eduarda Moreira Volpato, Rosana Souza Thurler dos Santos, Julio

David Spagnolo, Aline Magalhães Ambrosio, Denise Tabacchi Fantoni

Faculdade de Medicina Veterinária e Zootecnia, Universidade de São Paulo(USP), São Paulo, SP, Brasil

*Autor correspondente

e-mail: aline.engbruch@hotmail.com

\section{Resumo}

A miopatia pós-anestésica é uma das complicações anestésicas mais comuns na espécie equina e é caracterizada principalmente por claudicação de um membro até fraqueza generalizada do animal. Embora o problema tenha início durante o período transanestésico, os sinais clínicos só são vistos durante a recuperação pós-anestésica. É causada pela hipóxia muscular durante a anestesia, e entre os fatores predisponentes encontram-se: grande massa muscular do equino, longo tempo de decúbito, posicionamento ou acolchoamento inadequados, hipotensão arterial e hipoxemia. 0 objetivo deste trabalho é relatar um caso de miopatia pós-anestésica cuja provável causa não esteja relacionada aos fatores predisponentes observados. Foi encaminhada ao Serviço de Cirurgia de Grandes Animais uma égua, de 3 anos, da raça Brasileiro de Hipismo, $545 \mathrm{~kg}$, apresentando laceração de quartela do membro pélvico direito há um dia. Foi indicada a tenoscopia de urgência para lavagem da bainha flexora e exploração da ferida, a fim de evitar maior tempo de exposição a agentes infecciosos. Ao exame físico, apresentou-se agitada, com frequência cardíaca de 48 bpm, frequência respiratória $44 \mathrm{mpm}$, hematócrito 23\% e proteína plasmática total $6 \mathrm{~g} /$ dL. Apesar de diagnosticada a anemia normocítica hipocrômica ( $\mathrm{He}=5,2$ milhões $/ \mu \mathrm{L} \mathrm{Hb}=7,9 \mathrm{~g} / \mathrm{dL} \mathrm{CHCM}$ = 35\%), enquadrando, assim, o animal na classificação ASA III/V (American Society of Anestesiologists), o animal foi submetido à cirurgia. 0 protocolo anestésico utilizado foi detomidina (10 $\mu \mathrm{g} / \mathrm{kg}$, IV) como medicação pré-anestésica, indução com cetamina (2,5mg/kg, IV) e diazepam $(0,05 \mathrm{mg} / \mathrm{kg}$, IV) e, assim que o animal se apresentou em decúbito, foi administrado EGG $10 \%$ na dose de $50 \mathrm{mg} / \mathrm{kg}$ e posteriormente a intubação orotraqueal. 0 animal foi posicionado apropriadamente em mesa cirúrgica acolchoada, em decúbito lateral esquerdo, com o membro torácico esquerdo posicionado cranialmente e o membro pélvico esquerdo (MPE), caudalmente. A manutenção foi realizada com isofluorano e foi instituída ventilação mecânica controlada por volume. 0 paciente foi monitorado quanto à frequência e ritmo cardíaco, saturação 
periférica de oxihemoglobina $\left(\mathrm{SpO}_{2}\right)$ e pressão arterial invasiva por meio de monitor multiparamétrico. 0 animal apresentou somente dois curtos períodos de hipotensão, com PAM entre 50 a $60 \mathrm{mmHg}$, revertidos em até cinco minutos com infusão contínua de efedrina na taxa de $10 \mu \mathrm{g} / \mathrm{kg} / \mathrm{min}$ por dez minutos, seguida de $5 \mu \mathrm{g} / \mathrm{kg} / \mathrm{min}$ por cinco minutos. A $\mathrm{SpO}_{2}$ manteve-se em valores superiores a $98 \%$ e não houve alteração em nenhum outro parâmetro. Após três horas de anestesia geral, o animal foi levado à sala de recuperação pós-anestésica (RPA) em um colchão apropriado, em decúbito lateral esquerdo. Após 1h20min na RPA, assumiu posição esternal, e após dez minutos houve a primeira tentativa de colocar-se em estação. Mesmo com auxílio, houve muita dificuldade de propriocepção do MPE, deixando o animal agitado e com restrição de movimentação do mesmo, retornando ao decúbito esternal. 0 diagnóstico imediato da miopatia foi essencialmente clínico, devido à dificuldade do animal em se levantar, dor e rigidez muscular, e com o passar do tempo, também laboratorial. Instituiu-se tratamento imediato com massagens, laserterapia, fluidoterapia, miorrelaxante e analgésicos, além de auxílio com talha elétrica para levantar nos dias subsequentes. Após dois dias, apresentava creatinoquinase 24.310,0 U/L, atingindo $285.120 \mathrm{U} / \mathrm{L}$ no terceiro dia de pós-cirúrgico, quando ocorreu óbito por choque. Apesar de estar adequadamente posicionado e de não ter sofrido hipotensão arterial, o animal apresentava-se anêmico, com consequente redução da oferta de oxigênio aos tecidos, levando-o à hipóxia muscular e miopatia pós-anestésica. Conclui-se que nos casos de animais pesados e com grande massa muscular, e que têm alguma comodidade importante (neste caso, a anemia), há uma maior necessidade de corrigir o problema em questão antes da própria cirurgia.

Palavras-chave: Anestesia. Equinos. Anemia. 